\title{
Using a proteometabolomic approach to investigate the role of Dufour's gland in pheromone biosynthesis in the social wasp Polybia paulista
}

\author{
Franciele Grego Esteves, José Roberto Aparecido dos Santos-Pinto, \\ Daniel Menezes Saidemberg, Mario Sergio Palma* \\ Center of Study of Social Insects, Department of Biology, Institute of Biosciences of Rio Claro, São Paulo State University (UNESP), Rio Claro, SP 13500, Brazil
}

\section{A R T I C L E I N F O}

\section{Article history:}

Received 16 November 2015

Received in revised form 12 January 2016

Accepted 14 January 2016

Available online 22 January 2016

\section{Keywords:}

Mass spectrometry

GC-MS

Shotgun proteomics

Pheromone

Chemical communication

Metabolomics

\begin{abstract}
A B S T R A C T
Dufour's gland is associated with the venom apparatuses of social wasps and bees. This location and its evolutionary adaptations indicate that it could be involved in the production of alarm pheromones in the social wasp Polybia paulista. To investigate this hypothesis, the volatile composition of this gland was analyzed and compared to that in the venom. Eighteen compounds were identified as secreted by Dufour's gland, and 16 of these compounds were also identified in the venom, suggesting that the compounds produced by the gland are secreted and mixed with venom in the venom reservoir of this wasp. These compounds were subjected to a field bioassay to investigate their potential action as alarm pheromones. Alcohols and aldehydes elicited the alert behavior in workers, luring them outside the nest, whereas acids attracted the workers in the direction of the source; fatty acid methyl esters elicited aggression. These results suggest that Dufour's gland produces alarm pheromones. To corroborate this hypothesis the proteomic complement of this gland was assigned using a shot-gun strategy; 59 proteins were identified, and the results indicate specialization of Dufour's gland for the metabolism of fatty acids (elongation, esterification unsaturation, reduction, and decarboxylation) in the biosynthesis of alarm pheromones.

Biological significance: The present knowledge about the role of Dufour's gland among aculeate Hymenoptera insects suggests that it may have many different roles related to the biosynthesis and secretion of chemical markers for different biological functions, though none are related to the elicitation of alarm behaviors for coordinating a mass attack of the colony against intruders. The present study combined the analysis of secreted volatile compounds (as metabolites) with proteome assignments and a field bioassay with synthetic compounds to clearly demonstrate that Dufour's gland does in fact biosynthesize alarm pheromones in social wasps. This strategy may be reproduced in other investigations related to pheromone production in other insects.
\end{abstract}

(c) 2016 Elsevier B.V. All rights reserved.

\section{Introduction}

Colonies of social insects (wasps, bees, ants and termites) contain large amounts of immature brood forms and nectar dew among other types of forage reserves, which are very attractive as food for different predators [1]. To protect the colony from attack by predators, social insects have developed a series of strategies for communicating danger to their nest-mates $[2,3]$. The chemical communication of a danger within the vicinity of the colony is an important defensive strategy used by large colonies of honeybees and social wasps [2], whereby alarm pheromones are released together with venom during stinging attacks [4,5]. The release of alarm pheromones is also important for coordinating colony defense, including a massive attack against the predator [1]. In addition to be used in the defensive strategies,

\footnotetext{
* Corresponding author at: CEIS-IBRC-UNESP, Av. 24 A, no 1515, Bela Vista, Rio Claro, SP CEP 13506-900, Brazil.

E-mail address: mspalma@rc.unesp.br (M.S. Palma).
}

pheromones also play important roles in the control of social activities and communication among the social insects; these compounds maybe used to regulate many of the intra/extra-colonial activities of this arthropod group [6,7]. Pheromones are produced by a large number of exocrine glands that secrete them as volatiles compounds [6,7]. These compounds may signal sources of food for foraging, regulate access to the colony, determine caste-specific behaviors or inter-caste interactions, and elicit/coordinate defensive behaviors of the colony [8,9].

Dufour's gland is anatomically well developed in social insects, and its diverse biosynthetic capabilities contribute to the many different functions attributed to it. In social wasps, chemicals secreted by the gland appear to be involved in nest-mate recognition [10], egg marking [11], larval rearing, and even nest defense [12]. The alarm is initially communicated through a series of individual behaviors by guard workers, which perceive the presence of an intruder within the nest vicinity and may produce a pulsed vibration from wing buzzing and/ or scrape the nest surface with their mandibulae to alert nest-mates inside the hive of a potentially dangerous situation [13]. Chemical 
communication appears to be the second level of colony defense; indeed, the use of alarm pheromones is relatively common among social insects, which build large and complex colonies [2].

It has been demonstrated experimentally that alarm pheromones are released during the stinging action [4,5], and there are even some reports that alarm pheromones may be released into the air by defensive workers (guards) prior to an attack [6,7]. The release of alarm pheromones during an attack and/or at the site of wasp stinging serves to attract more workers to defend the colony in a coordinated action. In general, alarm pheromones are stored in the venom reservoir, together with toxins. Considering that both Dufour's gland and the venom gland are anatomically connected to the venom reservoir, the function of producing alarm pheromones to be used in the chemical communication of a danger to the colony has been attributed to this gland $[14,15]$. Such chemical communication can also be used to recruit nest-mates outside the nest for a coordinated attack against an intruder in the area of security around the nest [2]. Despite this evidence, the true function of Dufour's gland has been the subject of much speculation. Because this gland may have different roles in different groups of hymenopteran insects with different degrees of eusociality, we decided to investigate the involvement of Dufour's gland in the biosynthesis of alarm pheromones in the social wasp Polybia paulista. The gland in this species is well developed, and the colonies are large and complex, with alarm pheromones playing a very important defensive role. We evaluated the chemical profile of volatiles both from the venom and secretion from Dufour's gland and analyzed the proteomic complement of the gland to identify enzymes involved in the biosynthesis of alarm pheromones.

\section{Materials and methods}

\subsection{Chemicals}

All reagents were purchased from Sigma-Aldrich (Milan, Italy). A linear alkane series kit (C7-C34; Sigma-Aldrich) and fatty acids (C8:0C12:0, C13:0-C17:1 and C18:0-C20:5; Sigma-Aldrich) were used to optimize the GC $\times$ GC-MS method and to build a GC $\times$ GC hydrocarbon library. Hexane was purchased from TEDIA (95\% purity).

\subsection{Dufour's gland samples}

Workers of the social wasp P. paulista (Hymenoptera, Vespidae) were captured with a net from a geo-referenced nest at the São Paulo State University (UNESP) campus in Rio Claro, SP, Southeast Brazil $\left(22^{\circ} 23^{\prime} 42.5^{\prime \prime} \mathrm{S} 47^{\circ} 32^{\prime} 33.3^{\prime \prime} \mathrm{W}\right)$ and were immediately frozen and dissected. Dufour's gland was carefully punctured and extracted in a pre-treated glass tube containing $300 \mu \mathrm{L}$ hexane for $2 \mathrm{~min}$ at $28{ }^{\circ} \mathrm{C}$ with shaking. The extracts were centrifuged at $650 \times \mathrm{g}$ for $5 \mathrm{~min}$ at $25^{\circ} \mathrm{C}$. The supernatants were collected and immediately analyzed by GC-MS.

\subsection{Glassware and plastic pre-treatment}

Considering the sensitivity of the GC-MS system, it was necessary to use glassware and other materials that were completely clean and without contaminants (e.g., plasticizers, mold release agents or manufacturing waste). The materials were washed with hexane (95\% purity - TEDIA) for 60 min and then with a $0.5 \%(w / v)$ sodium hydroxide solution (SYNTH) for $60 \mathrm{~min}$; the material was then washed again with hexane for $60 \mathrm{~min}$. To check for possible contaminants, GC-MS analysis was performed on the solvents used in the various steps of glassware and plastic washing before the samples were analyzed.

\subsection{GC/MS analysis}

GG/MS analysis was carried out using a Shimadzu GC-MS quadrupole mass spectrometer system (mod. GCMS-QP2010 Ultra, Japan) with an RTx-5MS column (Restek, 5\% phenyl-95\% polidimethylsiloxane; $30 \mathrm{~m} \times 0.25 \mathrm{~mm}$ DI, $0.25 \mu \mathrm{m}$ ). The capillary column was temperatureprogrammed as follows. The column temperature ranged from $80^{\circ} \mathrm{C}$ to $270{ }^{\circ} \mathrm{C}$ in a non-linear gradient of $60 \mathrm{~min}$. The initial temperature was adjusted to $80^{\circ} \mathrm{C}$, held for $2 \mathrm{~min}$, gradually increased at $8{ }^{\circ} \mathrm{C} / \mathrm{min}$ to $130{ }^{\circ} \mathrm{C}$, held for $2 \mathrm{~min}$, increased at $8{ }^{\circ} \mathrm{C} / \mathrm{min}$ to $200{ }^{\circ} \mathrm{C}$, held for $8 \mathrm{~min}$, increased at $10^{\circ} \mathrm{C} / \mathrm{min}$ to $270{ }^{\circ} \mathrm{C}$, and finally held for $26 \mathrm{~min}$. The solvent delay was $5 \mathrm{~min}$, and the equilibrium time was $3 \mathrm{~min}$; the injection volume was $1 \mu \mathrm{L}$ in splitless (50 s) mode, and the injector temperature was set at $250{ }^{\circ} \mathrm{C}$ for the entire run. The carrier gas was helium (purity 99.995\%) delivered at a constant flow rate of $9 \mathrm{~mL} / \mathrm{min}$ at an initial pressure of $102.1 \mathrm{kPa}$. The sample was analyzed in full-scan mode at a scan speed of $1000 \mathrm{amu} / \mathrm{s}$ and a sampling frequency of 1 spectra/s over a mass range of $30-500 \mathrm{~m} / \mathrm{z}$. The interface and ion source temperatures were $280{ }^{\circ} \mathrm{C}$ and $280{ }^{\circ} \mathrm{C}$, respectively. The MS ionization mode parameters were as follows: electron ionization (EI), a filament bias of $-70 \mathrm{eV}$, and a detector voltage of $0.98 \mathrm{kV}$.

\subsection{Data analysis}

GC-MS solution software was used for instrument control and data processing. The National Institute of Standards and Technology (NIST) mass spectral library (version 11.0) and Shimadzu GC/MS Metabolites Spectral Database library were used for compound identification of each peak.

\subsection{Analysis of standard hydrocarbons}

The criteria used for reliable identification of each compound consisted of the following: i) a mass spectral match factor (S) of the deconvoluted mass spectra based on the NIST 11 library and Shimadzu GC/MS Metabolites Spectral Database Library higher than 870 (for experimental data presenting a signal-to-noise ratio $\geq 120$ ) and ii) linear retention index differences ( $\mathrm{I}=$ LRIexp - LRIlit $\leq \pm 25$ index units), where Rlexp is the retention index calculated for the first dimension of the GC-MS analysis and RIlit is the retention index reported in the literature for the RTx-5MS GC column or an equivalent column.

\subsection{Shotgun proteomics}

In-solution digestion was used for the shotgun strategy. For this purpose, the proteins $(100 \mu \mathrm{g})$ from Dufour's gland extracts were solubilized in $50 \mathrm{mM}$ ammonium bicarbonate, $\mathrm{pH} 7.9$, containing 7.5 M urea for $60 \mathrm{~min}$ at $37^{\circ} \mathrm{C}$ to denature the proteins, which were then reduced with $10 \mathrm{mM}$ DTT at $37^{\circ} \mathrm{C}$ for $60 \mathrm{~min}$. After this treatment, the proteins were alkylated with $40 \mathrm{mM}$ iodoacetamide at $25^{\circ} \mathrm{C}$ for $60 \mathrm{~min}$ in the dark. The samples were diluted five-fold with $100 \mathrm{mM}$ ammonium bicarbonate, $\mathrm{pH} 7.8$, and $1 \mathrm{M}$ calcium chloride was added to the samples to a final concentration of $1 \mathrm{mM}$. Non-autolytic trypsin (Promega) was added to the denatured protein solution (1:50 trypsin:protein, $w / w$ ) and incubated for $18 \mathrm{~h}$ at $37^{\circ} \mathrm{C}$. The samples were flash frozen in liquid nitrogen to quench the enzymatic digestion. The digested samples were desalted using an SPE C18 column (Discovery DSC-18, SUPELCO, Bellefonte, PA, USA) conditioned with $\mathrm{MeOH}$, rinsed with $1 \mathrm{~mL} \mathrm{0.1 \%}$ TFA and washed with $4 \mathrm{~mL}$ of $0.1 \%(v / v)$ TFA $/ 5 \%(v / v)$ ACN. Peptides were eluted from the SPE column with $1 \mathrm{~mL}$ of $0.1 \% \mathrm{TFA} / 80 \% \mathrm{ACN}$ and concentrated to dryness using a Speed-Vac. The digested samples were stored at $-80{ }^{\circ} \mathrm{C}$ until needed for analysis; the tryptic peptides were solubilized in 50\% ACN and subjected to nanoLC-ESI-CID analysis. 


\subsection{NanoLC-ESI-CID}

A Nano-Advance UHPLC system (Bruker Daltonics, Bremen, Germany) equipped with a PepMap100 C-18 trap column $(300 \mathrm{~mm} \times 5 \mathrm{~mm})$ and a PepMap100 C-18 analytical column $(75 \mathrm{~mm} \times 150 \mathrm{~mm}$ ) was used. The gradient was performed using the following mobile phases: A $(0.1 \%(v / v)$ formic acid; FA) in water $)$; B $(0.08 \%(v / v)$ FA in $A C N)$. The gradient was set to increase from 4 to $30 \%$ B over a time window from 0 to $105 \mathrm{~min}$ and then change to $80 \%$ B from 105 to $110 \mathrm{~min}$. The elution condition was then adjusted to recover the initial mobile phase, i.e., $4 \% \mathrm{~B}$ in the time window from 110 to 125 min. An Amazon ETD (Bruker Daltonics, Bremen, Germany) equipped with a CaptiveSpray source (Bruker Daltonics, Bremen, Germany) was used to record the peptide spectra over the mass range of $\mathrm{m} / \mathrm{z} 350-3500$ and $\mathrm{MS}^{2}$ spectra in information-dependent data acquisition mode over the mass range of $\mathrm{m} / \mathrm{z} 100-3500$. The MS spectra were recorded, followed by the acquisition of five datadependent CID MS/MS spectra generated from the three highest intensity precursor ions. An active exclusion of $0.4 \mathrm{~min}$ after two spectra was used to detect peptides in low abundance. The voltage between the ion spray tip and the spray shield was set to $1500 \mathrm{~V}$. The drying nitrogen gas was heated to $150^{\circ} \mathrm{C}$, and the flow rate was $10 \mathrm{~L} / \mathrm{min}$. Multiple charged peptides were chosen for the MS/MS experiments, and the collision energy was set automatically according to the mass and charge state of the peptides chosen for fragmentation due to their good fragmentation characteristics. The MS/MS spectra were interpreted, and peak lists were generated using DataAnalysis 4.1 (Bruker Daltonics).

\subsection{Protein identification}

For the shotgun proteomic analysis, MASCOT searches were conducted using MASCOT 2.2.06 (Matrix Science, London, UK) against the latest NCBI database (http://blast.ncbi.nlm.nih.gov, on October 3rd, 2015 ) initially restricted to the taxon Hymenoptera (863,152 entries). Proteins not identified were then subjected to new searches using the taxa Arthropoda (3,642,270 entries) and Nasonia (solitary wasp DB with 26,578 entries). Finally, the remaining proteins not identified were searched using the taxon Metazoa (15,023,936 entries). The search parameters were set as follows: taxonomy, enzyme selected as trypsin, 2 maximum missing cleavage sites allowed, peptide mass tolerance of $0.2 \mathrm{Da}$ for MS and 0.2 Da for MS/MS spectra, carbamidomethyl (C) specified as a fixed modification, and methionine oxidation specified in MASCOT as a variable modification. After protein identification, an error-tolerant search was performed to detect nonspecific cleavage. The proteins identified after the database search were subjected to additional filtering using Scaffold 4.3.2 (Proteome Software Inc., Portland, OR) to validate the peptide identification and to obtain a false discovery rate (FDR) of less than $1 \%$; FDR was calculated from forward and decoy matches by requiring significant matches for at least 2 distinct sequences. According to a local FDR algorithm implemented in Scaffold, the peptide probability was set to a minimum of $90 \%$, whereas the protein probability was set at $95 \%$. The databanks mentioned above were appended with common external contaminants from cRAP, a maintained list of contaminants, laboratory proteins and protein standards provided through the Global Proteome Machine Organization (http://www.thegpm.org/crap/index.html).

\subsection{Field bioassays}

The alarm behavior was observed according to different levels of colony behavior in relation to the danger posed by the presence of an intruder within the limit of security of the colony. Thus, the alarm behavior was observed at three levels, as based on the literature [16]: i) alert when workers are lured outside the nest; ii) attraction - when workers are attracted toward the direction of the source of the odor; iii) aggression - when workers attracted to the source of the odor sting the surface of the target used to apply the odor source.

The intruder in the field bioassay was represented by a wooden stick ( $2 \mathrm{~m}$ long) positioned $50 \mathrm{~cm}$ from the nest entrance; a black leather ball (the target, with total surface of $25 \mathrm{~cm}^{2}$ ) hung from the end of the stick by a $30 \mathrm{~cm}$ nylon string. To the surface of the target, $50 \mu \mathrm{L}$ of each volatile compound investigated (experimental group) was applied, and the behavior of the colony was monitored for five min after the stick was positioned in front of the colony. Used targets were replaced by fresh ones (not yet used) immediately after each assay; in fact, each target was used only once. Black leather balls without applied volatile compounds on the surface were used as the control. Three videocameras were positioned at different locations around the colony to permit counting i) the number of individuals (workers) attracted to within $25 \mathrm{~cm}^{2}$ of the nest surface around the entrance (alert behavior) and ii) the number of individuals flying in the direction of the target (attraction behavior). A grid lens covering a surface of $25 \mathrm{~cm}^{2}$ was adjusted over the camera lens to guide the observations and counting of individuals over the nest surface. The number of individuals stinging the target was registered after the 5 min observation because the stingers, which contain lateral barbs on the sting lancets, become attached to the target; thus, all workers that stung the target remained attached to its surface. The assay of each volatile compound was repeated five times, and the results are expressed as the means \pm S.D. of five experiments.

\subsection{Statistics}

Statistical significance was determined using GraphPad Prism, version 3.03 (La Jolla, CA), with Student's test to compare the control and experimental groups.

\section{Results}

The literature reports that alarm pheromones are released by social wasps mainly at the moment of stinging, together with the injection of venom into the victim $[10,11]$. Thus, to identify the composition of

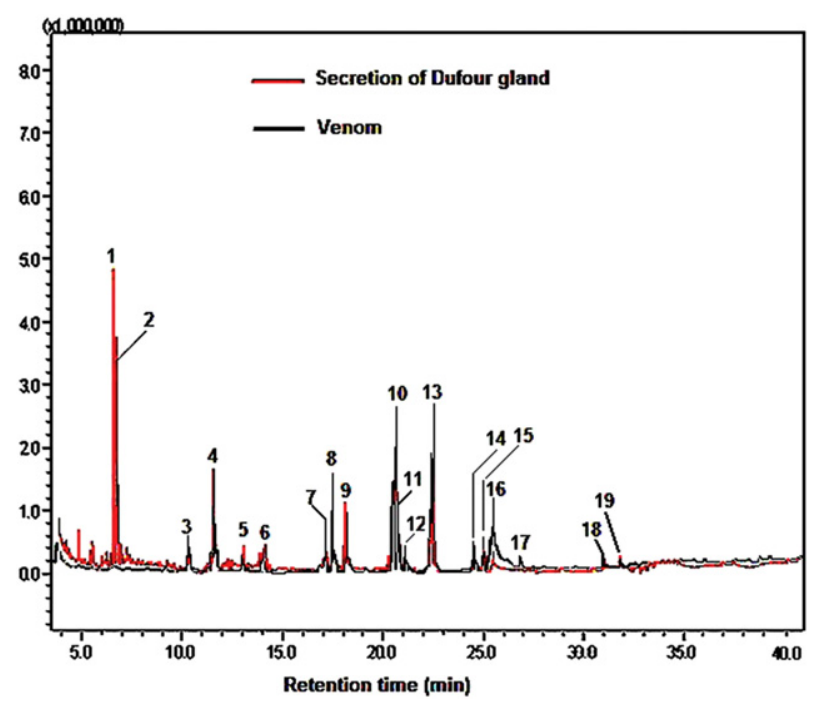

Fig. 1. Profile of the total ion chromatogram of the secretion of Dufour's gland (red line) and of the venom from the wasp P. paulista (black line) using an RTx-5MS column (Restek, 5\% phenyl-95\% polidimethylsiloxane; $30 \mathrm{~m} \times 0.25 \mathrm{~mm} \mathrm{DI}, 0.25 \mu \mathrm{m}$ ). The temperature ranged from $80^{\circ} \mathrm{C}$ to $270{ }^{\circ} \mathrm{C}$ in a non-linear gradient of $60 \mathrm{~min}$. The initial temperature was adjusted to $80^{\circ} \mathrm{C}$, held for $2 \mathrm{~min}$, gradually increased at $8{ }^{\circ} \mathrm{C} /$ min to $130{ }^{\circ} \mathrm{C}$, held for $2 \mathrm{~min}$, increased at $8{ }^{\circ} \mathrm{C} / \mathrm{min}$ to $200{ }^{\circ} \mathrm{C}$, held for $8 \mathrm{~min}$, increased at $10{ }^{\circ} \mathrm{C} / \mathrm{min}$ to $270{ }^{\circ} \mathrm{C}$, and finally held for $26 \mathrm{~min}$. The solvent delay was $5 \mathrm{~min}$, and the equilibrium time was $3 \mathrm{~min}$; the injection volume was $1 \mu \mathrm{L}$ in splitless $(50 \mathrm{~s})$ mode, and the injector temperature was set at $250{ }^{\circ} \mathrm{C}$ for the entire run. 
Table 1

Volatile compounds identified in the secretion of Dufour gland and in the venom from the social wasp $P$. paulista, by using GC/MS analysis.

\begin{tabular}{|c|c|c|c|c|}
\hline \multirow{2}{*}{ Peak } & \multirow{2}{*}{$\begin{array}{l}\text { Retention } \\
\text { time (min.) }\end{array}$} & \multicolumn{2}{|c|}{$\begin{array}{l}\text { Presence }(+) / \\
\text { absence }(-)\end{array}$} & \multirow{2}{*}{ Compound } \\
\hline & & $\begin{array}{l}\text { Dufour } \\
\text { gland }\end{array}$ & Venom & \\
\hline 1 & 6.35 & + & - & Decanal \\
\hline 2 & 6.76 & + & - & Decanol \\
\hline 3 & 10.41 & + & + & 9-Tridecenal \\
\hline 4 & 11.65 & + & + & Tetradecanal \\
\hline 5 & 13.08 & + & + & Tetradecanol \\
\hline 6 & 14.03 & + & + & Tridecanoic acid \\
\hline 7 & 17.02 & + & + & Tetradecanoic acid \\
\hline 8 & 17.41 & + & + & 8-Heptadecene \\
\hline 9 & 18.25 & + & + & $\begin{array}{l}\text { Tetradecanoic acid } \\
\text { methyl ester }\end{array}$ \\
\hline 10 & 20.74 & + & + & Hexadecanol \\
\hline 11 & 20.95 & + & + & Hexadecanoic acid \\
\hline 12 & 21.34 & + & + & 9-Ocatadecenol \\
\hline 13 & 22.61 & + & + & $\begin{array}{l}\text { Hexadecanoic acid } \\
\text { methyl ester }\end{array}$ \\
\hline 14 & 24.58 & + & + & Octadecanol \\
\hline 15 & 24.95 & + & + & Octadecanoic acid \\
\hline 16 & 25.58 & + & + & $\begin{array}{l}\text { Octadecanoic acid } \\
\text { methyl ester }\end{array}$ \\
\hline 17 & 26.90 & + & + & Eicosanoic Acid \\
\hline 18 & 31.03 & + & + & $\begin{array}{l}\text { Eicosanoic acid } \\
\text { methyl ester }\end{array}$ \\
\hline 19 & 31.94 & + & + & n.i. \\
\hline
\end{tabular}

n.i - non-identified compounds.

volatile compounds present in $P$. paulista venom and to compare it against the secretion from Dufour's gland, the exocrine fluids were analyzed by GC/MS. The profile of the total ion chromatogram (TIC) of both samples is shown in Fig. 1, revealing the presence of 19 peaks for the Dufour's gland secretion and 17 peaks for the venom. Fifteen of these compounds were identified using spectral interpretation based on comparison against commercial standard compounds (Sigma-Aldrich Co.), also analyzed under the same experimental conditions, as shown in Table 1. Peaks 1 and 2, identified as decanal and decanol, respectively, were found only in the Dufour's gland sample; the remaining volatile compounds were identified in both samples: tetradecanal (peak 4), tetradecanol (peak 5), tridecanoic acid (peak 6), tetradecanoic acid (peak 7), tetradecanoic acid methyl ester (peak 9), hexadecanol (peak 10), hexadecanoic acid (peak 11), hexadecanoic acid methyl ester (peak 13), octadecanol (peak 14), octadecanoic acid (peak 15), octadecanoic acid methyl ester (peak 16), eicosanoic acid (peak 17), and eicosanoic acid methyl ester (peak 18). Peak 19 was not identified. The compounds 9-tetradecenal (peak 3), 8-heptadecene (peak 8), and 9 -octadecenol (peak 12) were identified based only on comparison of their mass spectra to the NIST database (without standard compounds as references).

To verify whether the volatile compounds identified (Fig. 1 and Table 1) are in fact alarm pheromones, a series of bioassays was carried out. To this end, organic acids, aldehydes, alcohols, and methyl esters were used in model assays of aggression, in which alarm behaviors are observed. Some of the compounds used in the aggression assay corresponded to the volatiles found in the GC/MS analysis; other compounds corresponding to analogs with the same organic function, but presenting a different number of methylene groups, were also assayed to verify the minimal structural requirement to observe alarm behaviors. Alarm behavior was observed at three levels, as based on the literature: alert, attraction, aggression [14]. Fig. 2A shows a photograph of the $P$. paulista nest under alert behavior. Fig. 2B shows the colony under alert and attraction (several workers left the colony, while others flew around the target), and Fig. $2 \mathrm{C}$ shows some stinger workers attacking the target surface containing the source of the odor.
The frequencies of the three typical alarm behaviors elicited by the crude venom and the Dufour's gland secretion are shown in Fig. 2D; the effect of carboxylic acids, aldehydes/alcohols, and methyl esters are shown in Fig. 2E, F and G, respectively. The results suggest that alarm behaviors were elicited by both the venom and Dufour's gland secretion, with similar intensities (Fig. 2D). Some of the compounds identified in both samples (as well some of their analogs) were subjected to a field assay to verify whether they could individually elicit any of the alarm behaviors:

- the fatty acids hexadecanoic and octadecanoic acids (and some smaller carboxylic acids) elicited the alert and attraction behaviors at high frequencies and aggression at reduced frequencies (Fig. 2E);

- aldehydes (mainly decanal and tetradecanal) elicited high frequencies of alert but reduced attraction and aggression, and alcohols in general induced only small degree of alert behavior (Fig. 2F);

- methyl esters in general elicited high frequencies of all three alarm behaviors, including aggression (stinging) toward the targets, which was more pronounced with fatty esters (Fig. 2G).

The results suggest that the secretion from Dufour's gland is the source of the alarm pheromones found in P. paulista venom. To corroborate this observation, the proteomic profile of this gland's secretion was analyzed. Although no genomic information is available in databanks for social wasps, wasp proteins can be identified through cross-species data $[17,18]$. Accordingly, the extract of this gland was analyzed using a shotgun experimental strategy. After protein identification using MASCOT and additional filtering of the results with the algorithm Scaffold, we reliably identified 59 proteins with protein ID probabilities ranging from 98 to $100 \%$, as shown in Table S1. Approximately $50 \%$ of these identifications correspond to insect protein accessions. Based on the biological processes involved (Table S1), 44\% of the proteins identified in the Dufour's gland secretion are related to the ox-redox process, $20 \%$ to fatty acid metabolism, $19 \%$ to general lipid metabolism and 5.5\% to alcohol metabolism; 5.5\% are acyltransferases and $4 \%$ general hydrolases, and $2 \%$ are involved in sterol biosynthesis (Fig. 3).

Many of the volatiles identified in the venom and the secretion of Dufour's gland are fatty compounds, largely products of the fatty acid elongation pathway as well as fatty acid reduction, methyl fatty ester synthesis, and unsaturated fatty acid biosynthesis, and some enzymes belonging to these metabolic pathways were identified among the proteins (see Table S1) and selected (Table 2) for further discussion.

\section{Discussion}

Dufour's gland and the venom gland are associated with the sting apparatus in female aculeate wasps and bees; despite this, no role have been attributed to the former in terms of venom activity. It appears that Dufour's gland has different functions in different Hymenoptera groups: secreting chemicals to be used in diverse processes of chemical signaling in different taxa, from markers in nest building and larval care to pheromones involved in communicative functions in social species [19], including nest defense [20]. During evolution, this gland appears to have undergone many different adaptations/modulations, which may have influenced its biosynthetic capability in different Hymenoptera groups according to the type of ecological interaction of each species [21]. However, the contribution of Dufour's gland to the production of alarm pheromones has not been properly investigated to date. Thus, the present study addresses the possibility that Dufour's gland in the social wasp P. paulista produces and secretes volatile compounds into the venom reservoir for use as alarm pheromones. To verify this hypothesis, the secretion of Dufour's gland was analyzed by GC/MS, and its composition was compared to that of the venom reservoir; all the volatile compounds identified in the venom (which are released 


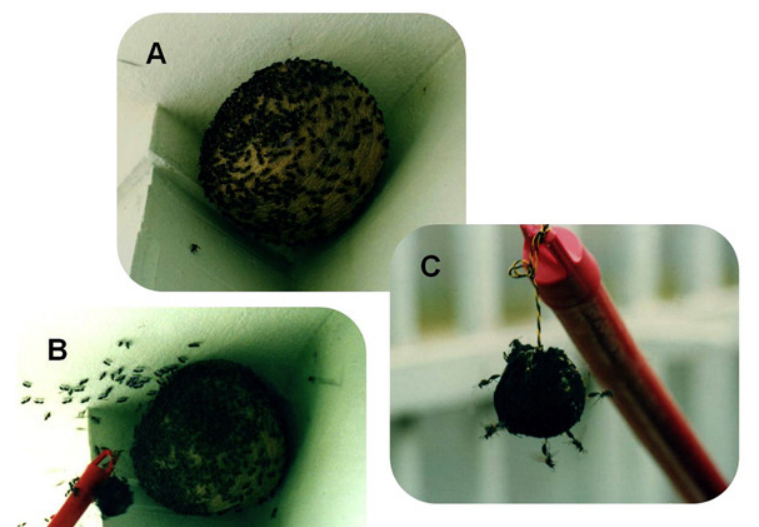

D

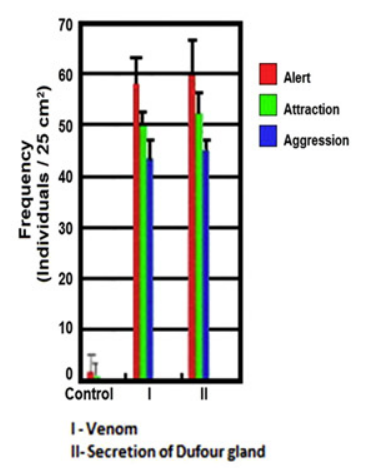

$\mathbf{F}$

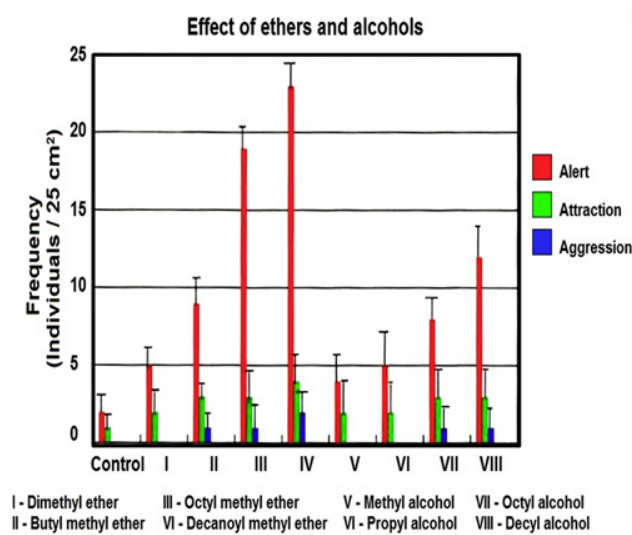

E

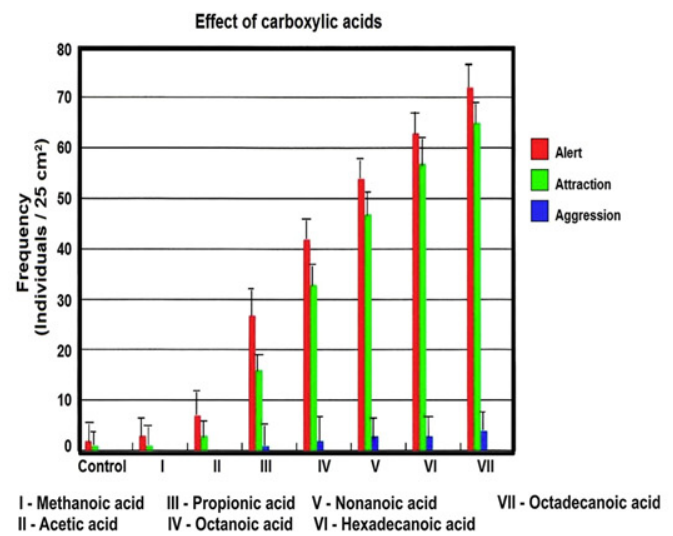

G

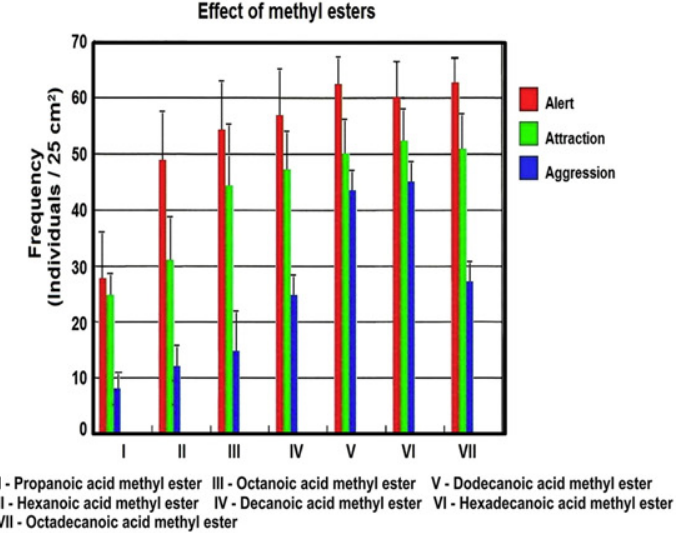

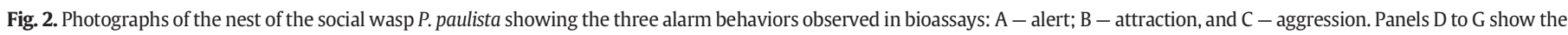

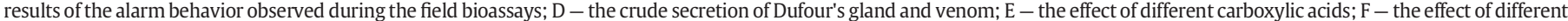
aldehydes and alcohols; and $\mathrm{G}$ - the effect of different methyl ester compounds.

during stinging) were also present in the Dufour's gland secretion (Fig. 1 and Table 1). It is important to emphasize that the compounds decanal and decanol, which were present in the Dufour's gland secretion, were
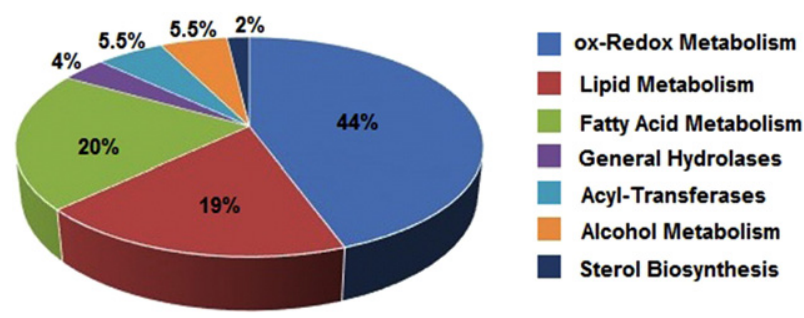

Fig. 3. Distribution of metabolic functions of the proteomic complement of Dufour's gland from the wasp P. paulista according to Gene Ontology DB searches. absent from the venom. The secretion of Dufour's gland changes according to the hymenopteran group, and the composition has been reported to contain long-chain saturated and unsaturated hydrocarbons, terpenoids, alcohols, esters, long-chain fatty acids, aldehydes, some aromatic compounds, and cholesterol [19], which appears to be consistent with the volatile compounds reported in the present study.

Previous studies identified different organics as active components of alarm pheromones in the venom of different species of social wasps: i) a mixture of spiroacetals in Polybia occidentalis, Polybia sericia [22], and Ropalidia flavopicta [17]; ii) N-(3-methylbutyl) acetamide in Vespula maculifrons and V. Vespula squamosa [23,24]; iii) 2-methyl-3buten-2-ol in Vespa crabro [25]; iv) a mixture of alkanes, monounsaturated alkenes and 2-alcohols in Polybioides raphigastra [26].

Apparently, the organic functions of the alarm pheromones observed in P. paulista are very different from those reported in other 
Table 2

Protein identification related to biosynthesis of unsaturated fatty acids and fatty acid metabolism of the Dufour's gland from Polybia paulista wasp by shotgun proteomic analysis.

\begin{tabular}{|c|c|c|c|c|}
\hline $\begin{array}{l}\text { Accession } \\
\text { number }\end{array}$ & Protein & $\begin{array}{l}\text { MW } \\
(\mathrm{kDa})\end{array}$ & Sequence peptides & $\begin{array}{l}\text { Score } \\
\text { (protein ID probability) }\end{array}$ \\
\hline NP_477378.1 & Acetyl-CoA acyltransferase 2 & 54 & PSAPVR; EFTYVSQDPK & $100 \%$ \\
\hline ETN62152 & 3-Hydroxyacyl-CoA dehydrogenase & 90 & IATKDSK; DATEAGLAR & $100 \%$ \\
\hline XP_001123353 & Enoyl-CoA hydratase & 34 & PQYFASDTK; AMEMVLTGK & $99 \%$ \\
\hline XP_395130 & Mitochondrial trans-2-enoyl-CoA reductase & 41 & APHIHR; LLETLFVHR & $100 \%$ \\
\hline XP_624056 & Fatty acyl-protein thioesterase 2 & 36 & NDLIGLK; FPEHNVK & $100 \%$ \\
\hline XP_006614830 & Elongation of very long chain fatty acids protein 4-like (ELOVL4) & 36 & HRKAFK; QLEKRRQADAAAAK & $98 \%$ \\
\hline XP_002002076 & Very-long-chain 3-oxoacyl-CoA reductase & 36 & IAVVVIAAVGLR; QVLPGMMER & $100 \%$ \\
\hline NP_609534 & Very-long-chain (3R)-3-hydroxyacyl-CoA dehydratase & 28 & VDLINVK; DIDVYFGDK; ISALTWLR & $100 \%$ \\
\hline XP_006613992 & Very-long-chain enoyl-CoA reductase & 35 & QQLHSLK; APYAQR & $100 \%$ \\
\hline KOX78630 & Aldehyde dehydrogenase (NAD +) & 56 & AVAAAK; TMDASVR; VLSLIK & $100 \%$ \\
\hline XP_006558758 & Alcohol dehydrogenase & 46 & AAVAWK; IDPTAPLDK; PFQLVTGRVWK & $100 \%$ \\
\hline M4NBK1 & $\begin{array}{l}\text { LOC724216 [Apis mellifera] - protein presenting } \\
\text { O-methyltransferase domain }\end{array}$ & 33 & MFLVEEYVK; ELILPNLSPEAK; HIMAIN PFISR & $100 \%$ \\
\hline A9YRX5 & Acyl-CoA ( $\Delta$-9-desaturase $)$ & 41 & GFFSHIGWLLVR; YSETDADPHNATR & $100 \%$ \\
\hline Q5KR51 & Cytochrome P450 2E2 variant 2 & 57 & NVPKSLTK; YLPGNHR & $100 \%$ \\
\hline Н9J5B2 & NADH-cytochrome b5 reductase & 45 & YENSLKY; IYLSESSDEFPSK & $100 \%$ \\
\hline
\end{tabular}

species of social wasps and bees, revealing a high plasticity of the secretions produced by the Dufour gland among the social Hymenoptera [15].

To investigate the action of the volatile compounds identified in the secretion of Dufour's gland as alarm pheromones, a Dufour's gland extract, the venom of P. paulista and 22 synthetic compounds (carboxylic acids, fatty acids, aldehydes, and alcohols), were assayed for typical alarm behaviors: alert (at the level of the nest surface) (Fig. 2A), attraction (flight) of defensive workers toward the direction of the odor source on the surface of a target (Fig. 2B), and attack (stinging against the target surface) (Fig. 2C). The last behavior was very easy to observe because after stinging the target, the workers became attached to the surface due to the presence of barbs on the sting lancets, which do not permit removal of the stinger, as shown in Fig. 2C.

The crude extracts of Dufour's gland elicited the three alarm behaviors in intensities similar to those observed for the crude venom, suggesting that Dufour's gland contains volatile compounds that induce alarm behavior in the social wasp P. paulista (Fig. 2D). Among the 22 synthetic compounds assayed, six corresponded to compounds identified in the GC/MS analysis of the Dufour's gland secretion and venom: decanal, tetradecanal, hexadecanoic acid, octadecanoic acid, hexadecanoic acid methyl ester, and octadecanoic acid methyl ester. The remaining compounds were used in the assays to investigate whether only fatty compounds were able to induce alarm behavior and to verify the minimal chemical structure necessary to elicit alarm behaviors. The results (Fig. $2 \mathrm{D}$ to $2 \mathrm{G}$ ) revealed that alcohols induced some alerts in the colony but very little or no aggression (Fig. 2F). Aldehydes induced increasing levels of alert with an increase in the number of methylene groups; the highest frequencies of alert were observed for fatty aldehydes (dodecanal and tetradecanal) (Fig. 2F). Carboxylic acids caused increasing frequencies of alert and attraction toward the target, but no significant level of aggression (Fig. 2E); the highest frequencies of these behaviors were induced by the fatty acids hexadecanoic acid and octadecanoic acid. The bioassay of methyl esters revealed that these compounds elicited the three alarm behaviors at high frequencies (Fig. 2G); the behaviors of alert and attraction increased significantly from propionic acid methyl ester to decanoic acid methyl ester, remaining stable at high frequencies up to octadecanoic acid methyl ester. However, the level of aggression increased up to dodecanoic acid methyl ester, remained stable up to hexadecanoic acid methyl ester, but decreased for octadecanoic acid methyl ester. These results clearly suggest a relationship among organic functions and the three alarm behaviors, i.e., an ester is more active than a carboxylic acid, which is more active than an aldehyde, which is more active than an alcohol. It must be emphasized that only methyl esters elicited significant aggression; in addition, the number of methylene groups present on the volatile compounds appeared to modulate the intensity of the alarm behaviors, i.e., an increasing number of methylene units was accompanied by a rise in the frequency of the behaviors. Fatty compounds with $12 \mathrm{C}$ to $16 \mathrm{C}$ apparently correspond to the more active ones.

Considering that the secretion of Dufour's gland appears to be the source of alarm pheromones in P. paulista, the proteomic profile of this gland was analyzed to verify whether the proteome complement can support the metabolism of the compounds related to alarm behaviors. The shotgun approach implemented permitted the identification 59 proteins, of which 55\% correspond to typical mitochondrial enzymes, predominantly related to fatty acid metabolism (Fig. 3 and Table S1). The identification of tetradecanoic acid, hexadecanoic acid, octadecanoic acid, and eicosanoic acid suggests the presence of the fatty acid elongation pathway in Dufour's gland cells. Table 2 summarizes the proteome complement of the Dufour's gland extract shown in Table S1, emphasizing the presence of certain enzymes related to the metabolism of fatty acids. Table 2 lists the proteins present, acetyl-CoA acyltransferase, 3-hydroxyacyl-CoA reductase, enoyl-CoA hydratase, trans-2-enoyl-CoA reductase, fatty acid acylprotein thioesterase, elongation of very long-chain fatty acid protein, very long-chain-3-oxoacyl-CoA reductase, very long-chain-(3R)-3hydroxyacyl dehydrogenase, and very long-chain enoyl-CoA reductase. These enzymes correspond to all of those of the two fatty acid elongation pathways: i) the mitochondrial route - elongating short carboxylic acids and long-chain fatty acids (from butanoic acid to tetradecanoic acid in five catalytic steps); ii) the endoplasmic reticulum route - elongating very long-chain fatty acids (hexadecanoic acid is the initial substrate), also in five catalytic steps. Each elongation cycle in both routes incorporates two methylene units into the chain [27]. These routes are illustrated in Fig. 4, and the catalytic reactions of each enzyme can be summarized as follows.

Mitochondrial route

- step 1: acetyl-CoA acyltransferase 2, also known as 3-ketoacyl-CoA thiolase, catalyzes the reaction:

acyl-CoA + acetyl-CoA $\rightleftharpoons$ CoA +3 -oxoacyl-CoA

- step 2: 3-hydroxyacyl-CoA dehydrogenase catalyzes the reaction:

long-chain-3-oxoacyl-CoA $+\mathrm{NADH} \rightleftharpoons$ long-chain $(\mathrm{S})$-3-hydroxyacyl$\mathrm{CoA}+\mathrm{NAD}^{+}$

- step 3: enoyl-CoA hydratase catalyzes the reaction:

long-chain (3S)-3-hydroxyacyl-CoA $+\mathrm{NAD} \rightleftharpoons$ long-chain trans-2enoyl-CoA + NADH 


\section{FATTY ACIDS ELONGATION}

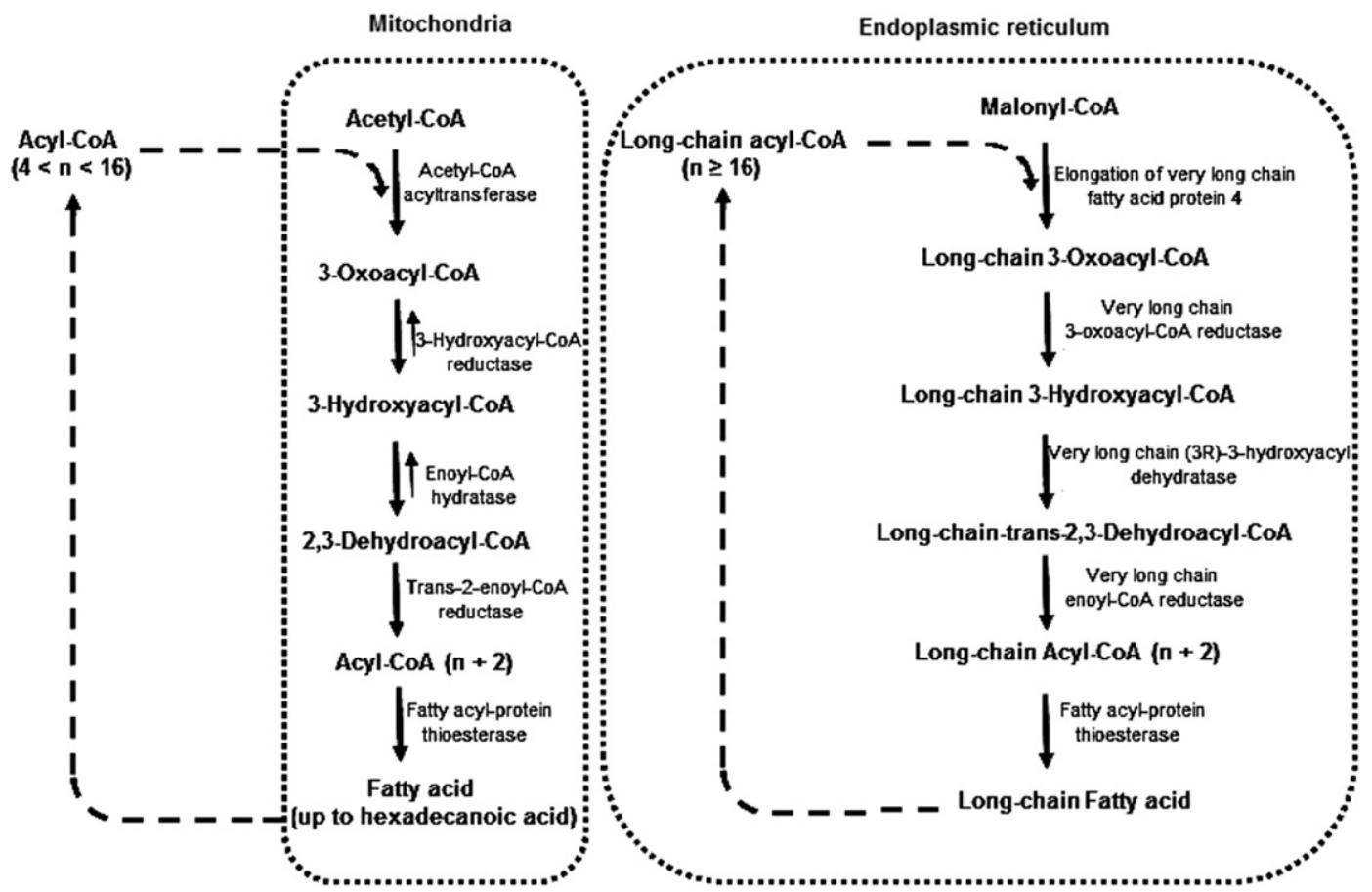

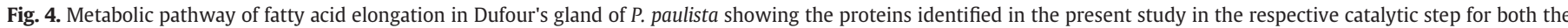
mitochondria and endoplasmic reticulum pathways.

- step 4: trans-2-enoyl-CoA reductase catalyzes the reaction:

trans-2,3-dehydroacyl-CoA $+\mathrm{NADPH} \rightleftharpoons$ acyl-CoA $+\mathrm{NADP}^{+}$

- step 5: fatty acyl[protein carrier] thioesterase 2 catalyzes the removal of thioester-linked fatty acyl groups from modified residues in fatty acid protein carrier:

fattyacyl $-[$ proteincarrier $]+\mathrm{H}_{2} \mathrm{O} \rightleftharpoons$ fattyacid +

(protein)

\section{Endoplasmic reticulum route}

- step 1: elongation of very long-chain fatty acid is achieved by protein 4-like (ELOVL4) catalyzing the reaction:

very long-chain acyl-CoA + malonyl-CoA $\rightleftharpoons \mathrm{CoA}+$ very long-chain 3oxoacyl-CoA

- step 2: very long-chain 3-oxoacyl-CoA reductase catalyzes the reaction:

very long-chain 3-oxoacyl-CoA $+\mathrm{NADPH} \rightleftharpoons$ very long-chain $(3 \mathrm{R})-3$ hydroxyacyl-CoA $+\mathrm{NADP}^{+}$

- step 3: very long-chain (3R)-3-hydroxyacyl-CoA dehydratase catalyzes the reaction:

very long-chain $(3 \mathrm{R})-3$-hydroxyacyl-CoA $\rightleftharpoons$ very long-chain trans-2,3dehydroacyl-CoA $+\mathrm{H}_{2} \mathrm{O}$

- step 4: very long-chain enoyl-CoA reductase catalyzes the reaction: very long-chain trans-2,3-dehydroacyl-CoA + NADPH $\rightleftharpoons$ very-longchain acyl-CoA + NADP ${ }^{+}$

- step 5: fatty acyl[protein carrier] thioesterase 2 catalyzes the removal of thioester-linked fatty acyl groups from modified residues in fatty acid protein carrier:

fattyacyl - [proteincarrier $]+\mathrm{H}_{2} \mathrm{O} \rightleftharpoons$ fattyacid +

(protein)

The behavioral assay of alarm revealed methyl esters, mainly those of fatty acid origin, as the most active components among alarm pheromones, eliciting the three alarm behaviors at high frequencies (Fig. 2D to $G$ ). A careful observation of Table 1 reveals four methyl esters among the volatile compounds identified in the secretion of Dufour's gland and in the venom of P. paulista, tetradecanoic acid methyl ester, hexadecanoic acid methyl ester, octadecanoic acid methyl ester, and eicosanoic acid methyl ester, indicating that the esterification of fatty acids must represent an important metabolic conversion in the production of alarm pheromones. The conversion of organic acids to methyl esters is generally catalyzed by enzymes generically known as o-methyl transferases, which are very common in diverse organisms and catalyze the methylation of small carboxylic acids to generate large macromolecules [28]. A protein presenting an o-methyltransferase domain was identified in the proteomic complement of Dufour's gland (Table 2), suggesting that this enzyme may be responsible for the methylation of the long and very long fatty acids present in this gland's secretion, as represented in Fig. 5. The generic reaction catalyzed by this enzyme is:

S-adenosyl-L-methionine + fatty acid $\rightleftharpoons$ S-adenosyl-L-homocysteine + fatty acid methyl ester.

In invertebrates, different forms of this enzyme are involved in the biosynthesis of juvenile hormone; therefore, o-methyltransferases 

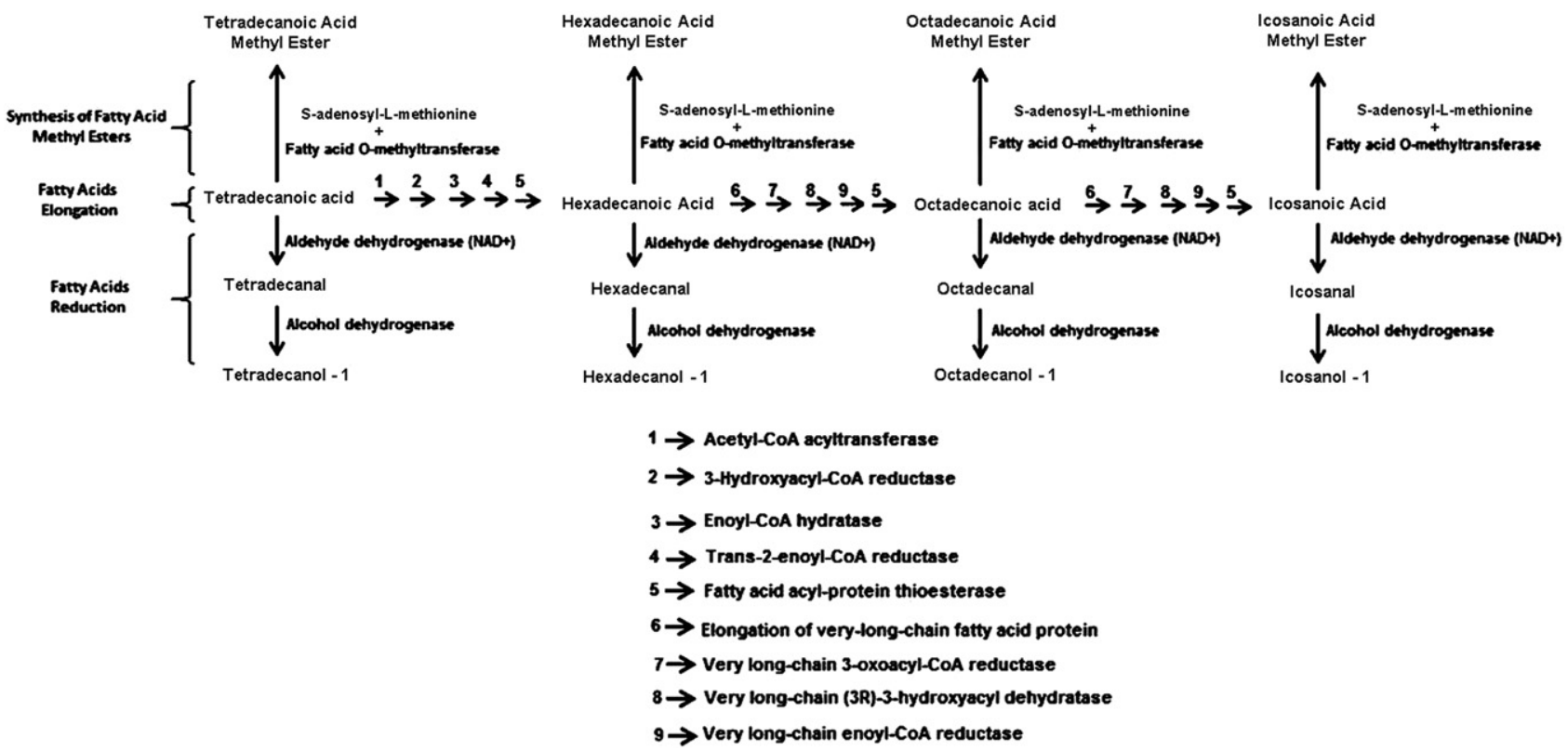

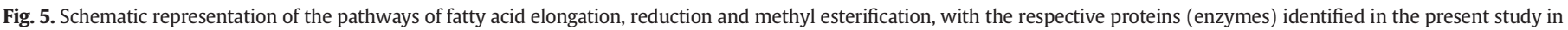
Dufour's gland of $P$. paulista.

play important regulatory roles in growth, development, and defense $[28,29,30,31]$. To our knowledge, the present study reports for the first time the occurrence of an o-methyltransferase in Dufour's gland. Table 1 also reveals the presence of some fatty aldehydes and fatty alcohols in the secretion of Dufour's gland and in the venom of $P$. paulista, which largely elicited the alert behavior in the workers (Fig. 2F). However, these types of compounds are not common in the normal diet of social wasps [32]; thus, the most probable origin of these compounds in the Dufour's gland secretion is through the metabolic reduction of fatty acids to fatty aldehydes, followed by another reduction to alcohols. Table 2 includes two enzymes directly involved in these transformations, aldehyde dehydrogenase and alcohol dehydrogenase, as shown in Fig. 5. Aldehyde dehydrogenase catalyzes the reaction:

fatty acid $+\mathrm{NADPH}+\mathrm{ATP} \rightleftharpoons$ aldehyde $+\mathrm{NADP}^{+}+$diphosphate $+\mathrm{H}_{2} \mathrm{O}$ and alcohol dehydrogenase catalyzes the reaction:

aldehyde $+\mathrm{NADPH} \rightleftharpoons$ alcohol $+\mathrm{NADP}^{+}$.

Although unsaturated fatty compounds were not assayed in the present investigation, some were identified both in the secretion of Dufour's gland and in the venom of $P$. paulista (9-tridecenal and 9octadecenol in Table 1) and may even have some role as alarm pheromones. The unsaturation of fatty compounds typically occurs via enzymes generically known as desaturases [33,34,35]. Six different forms of desaturases were observed in the proteomic complement of Dufour's gland: acyl-CoA- $\Delta$-9-desaturase and $\Delta$-12-desaturase $\left(\mathrm{FAD}^{+}\right)$ (Table 2), stearoyl-CoA desaturase ( $\Delta$-9-desaturase), acyl-CoA Z10 desaturase, two generic acyl-CoA desaturases, and stearoyl-CoA desaturase ( $\Delta$-9-desaturase) (Table S1). The compounds 9-tridecenal and 9-octadecenol (Table 1 ) are fatty acid derivatives, unsaturated at position 9 , which appears to be compatible with the presence of $\Delta-9$ desaturases in the cells of Dufour's gland. The presence of other desaturases is a strong indication that the gland has an intense demand for the unsaturation of other types of aliphatic and aromatic compounds in addition to fatty ones. Table 1 presents the identification of an unsaturated hydrocarbon (8-heptadecene), which was not assayed for alarm behaviors, that appears to be compatible with the chemical structure of cuticular hydrocarbons of the tegument of social Hymenoptera in general (acting as a marker for nest-mate recognition in these insects); these hydrocarbons are produced in the pathway of unsaturated hydrocarbon biosynthesis [36], a multistep catalytic route that utilizes fatty compounds as substrates and among a series of enzymes also requires the presence of proteins such as stearoyl-CoA desaturase $(\Delta$-9-desaturase) (Table S1) and sometimes also NADH-cytochrome b5 reductase (depending on the type of substrate) (Table 2). The cytochrome P450 complex (also known as CYP4G) (Table 2) catalyzes the decarboxylation of fatty compounds [37], leading to the formation of the final metabolite of this route: an unsaturated hydrocarbon presenting an odd number of carbons (Fig. 6). Therefore, the presence of octadecanoic acid and 8-heptadecene as well stearoyl-CoA desaturase

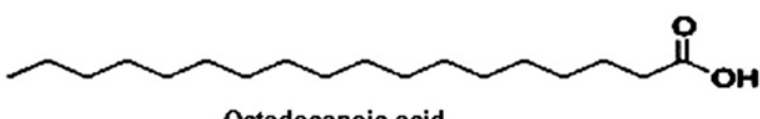

Octadecanoic acid StearoyL-CoA desaturase $(\Delta-9$-desaturase $)$
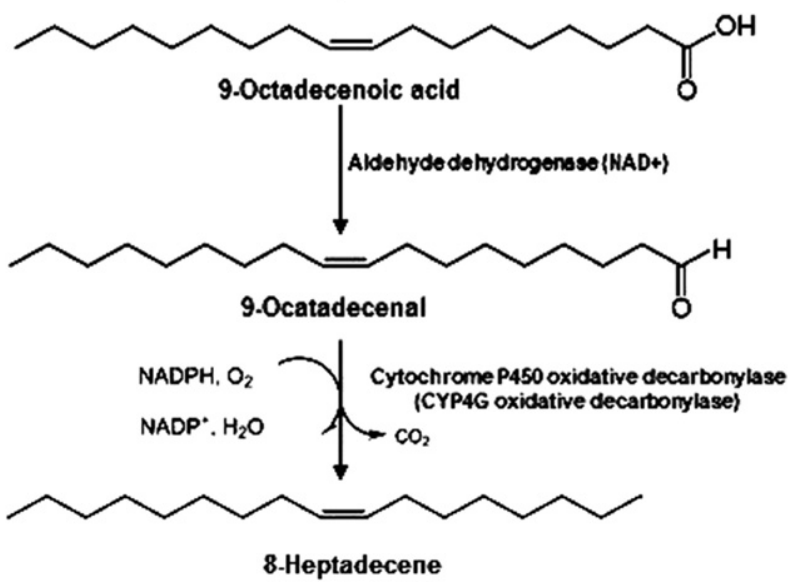

Fig. 6. Schematic representation of the pathway of unsaturated alkene biosynthesis, with the respective proteins identified in the present study for Dufour's gland of P. paulista. 
( $\Delta$-9-desaturase), aldehyde dehydrogenase and CYP4G in the proteome of Dufour's gland suggests that this gland also may be involved in the biosynthesis of some cuticular unsaturated hydrocarbons.

\section{Conclusion}

The present investigation focuses on the possible involvement of Dufour's gland of the social wasp P. paulista in the biosynthesis of volatile compounds that are secreted and mixed with venom components. When the wasp stings an intruder, the volatiles (composed of a mixture of 19 major compounds) elicit three alarm behaviors in the workers defending the colony to coordinate a massive attack if necessary. The most active components among the volatiles were found to be fatty acid methyl esters, followed by long-chain fatty acids and fatty alcohols. To corroborate that Dufour's gland in fact produces the volatiles, the proteomic complement of this gland was analyzed using a shotgun strategy, clearly demonstrating the presence of all enzymes involved in fatty acid elongation (in the mitochondria and endoplasmic reticulum). Additionally, the protein responsible for the biosynthesis of fatty acid methyl esters, as well those involved in the reduction of acids to aldehydes and alcohols, were identified. Dufour's gland also may be involved in the biosynthesis of some unsaturated fatty acids. The proteometabolomic profile of Dufour's gland of the social wasp $P$. paulista was analyzed, providing strong clues about the role of this gland in the production of alarm pheromones in this wasp.

Supplementary data to this article can be found online at http://dx. doi.org/10.1016/j.jprot.2016.01.009.

\section{Conflict of interest}

The authors declare no conflict of interests.

\section{Transparency document}

The Transparency document associated with this article can be found, in online version.

\section{Acknowledgments}

This work was supported by grants from FAPESP (Proc. 2011/516841) and CNPq. M.S.P. is a researcher from the National Research Council of Brazil-CNPq; J.R.A.S.P. is a postdoc research fellow from FAPESP, and F.G.E. is a postgraduation fellow from FAPESP at São Paulo State University-UNESP, Rio Claro, Brazil.

\section{References}

[1] A. Fortunato, F.R. Dani, M.F. Sledge, S. Fondelli, S. Turillazzi, Alarm communication in Ropalidia social wasps, Insect. Soc. 51 (2004) 299-305.

[2] C.K. Starr, Holding the Fort: colony defense in some primitively social wasps, in: E. DL, S. JO (Eds.), Insect Defenses - Adaptative Mechanisms and Strategies of Prey and Predators, State Univerity of New York Press, Albany, USA 1990, p. 482.

[3] H.R. Hermann, Defensive Mechanisms in Social Insects, Praeger, New York, 1984 259.

[4] R.L. Jeanne, Evidence for an alarm substance in Polistes canadensis, Experientia 38 (1982) 329-330.

[5] D.C. Post, H.A. Downing, R.L. Jeanne, Alarm response to venom bu social wasps Polistes exclamans and P. fuscatus (Hymenoptera: Vespidae) J, Chem. Ecol. 10 (1984) 1425-1433.

[6] J.B. Free, Pheromones of Social Bees, University Press/Chapman and Hall, London, 1987.

[7] M.S. Blum, in: J.M. Graham (Ed.), The Hive and the Honey Bee, Dadant and Sons, Hamilton 1992, p. 373.

[8] K.N. Slessor, L.-A. Kaminski, G.G.S. King, J.H. Borden, W. ML, Nature (1988) 332-354.

[9] M.S. Blum, H.M. Fales, in: Needham (Ed.), In: Africanized Honeybee and Bee Mites, Ellis Horwood, Chichester 1988, p. 141.
[10] F.R. Dani, S. Fratini, S. Turillazzi, Behavioural evidence for the involvement of Dufour's gland secretion in nestmate recognition in the social wasp Polistes dominulus. (Hymenoptera, Vespidae), Behav. Ecol. Sociobiol. 38 (1996) 311-319.

[11] H.A. Downing, The function and evolution of exocrine glands, in: R. KJ, M. RW (Eds.), The Social Biology of Wasps, Cornell University Press, Ithaca, London 1991, pp. 540-569.

[12] S. Turillazzi, The stenogastrinae, in: K.G. Ross, R.W. Matthews (Eds.), The Social Biology of Wasps, Ithaca, Cornell University press 1991, pp. 74-98.

[13] R. Chadab, Early warning cues for social wasps attacked by army ants, Psyche 86 (1979) 115-123.

[14] R.L. Jeanne, Social biology of neotropical wasp Myschocyttarus drewsenii, Bull. Mus Comp. Zool. 144 (1972) 63-170.

[15] T. Katzav-Gozansky, V. Soroker, A. Hefetz, Plasticity of caste-specific Dufour's gland secretion in the honey bee (Apis mellifera L.), Naturwissenschaften 84 (1997) 238-241.

[16] R.L. Jeanne, Alarm recruitment, attack behavior, and the role of the alarm pheromone in Polybia occidentalis (Hymenoptera: Vespidae), Behav. Ecol. Sociobiol. 9 (1981) 143-148.

[17] A.J. Liska, A. Shevchenko, Expanding the organismal scope of proteomes: crossspecies protein identification by mass spectrometry and its implications, Proteomics 3 (2003) 19-28.

[18] L.D. Santos, K.S. Santos, J.R.A. Santos-Pinto, N.B. Dias, B.M. De Souza, J. Perales, G.B. Domont, F.M. Castro, J.E. Kalil, M.S. Palma, Profiling the proteome of the venom from the social wasp Polybia paulista: a clue to understand the envenoming mechanism, J. Proteome Res. 9 (2010) 3867-3877.

[19] A. Mitra, Function of the Dufour's gland in solitary and social Hymenoptera, J. Hymenopt. Res. 35 (2013) 33-58.

[20] J.P.J. Billen, New structural aspects of the Dufour's gland and venom gland in social insects, Naturwissenschaften 74 (1987) 340-341.

[21] F.C. Abdalla, C. Cruz-Landim, Dufour glands in the hymenopterans (Apidae, Formicidae, Vespidae): a review, Rev. Bras. Biol. 61 (1) (2000) 95-106.

[22] F.R. Dani, R.L. Jeanne, S.R. Clarke, G.R. Jones, E.D. Morgan, W. Francke, S. Turillazzi, Chemical characterization of the alarm pheromone in the venom of Polybia occidentalis and of volatiles from the venom of P. sericea, Physiol. Entomol. 25 (2000) 363-369.

[23] R.R. Heath, P.J. Landolt, The isolation, identification and synthesis of the alarm pheromone of Vespula squamosa (Drury) (Hymenoptera: Vespidae) and associated behavior, Experientia 44 (1988) 82-83.

[24] P.J. Landolt, R.R. Heath, H.C. Reed, K. Manning, Pheromonal mediation of alarm in the eastern yellow jacket (Hymenoptera: Vespidae), Fla. Entomol. 78 (1995) $101-108$.

[25] H.J. Veith, N. Koeniger, U. Maschwitz, 2-Methyl-3-buten-2-ol, a major component of the alarm pheromone of the hornet Vespa crabro, Naturwissenschaften 71 (1984) 328-329.

[26] M.F. Sledge, F.R. Dani, A. Fortunato, U. Maschwitz, S.R. Clarke, E. Francescato, R. Hashim, E.D. Morgan, G.R. Jones, S. Turillazzi, Venom induces alarm behaviour in the social wasp Polybioides raphigastra: an investigation of alarm behaviour. venom volatiles, and sting anatomy, Physiol. Entomol. 24 (1999) 234-239.

[27] M. Kanehisa, S. Goto, KEGG: Kyoto enciclopedia of genes and genomes, Nucleic Acids Res. 28 (2000) 27-30.

[28] D.X. Li, X.J. Du, X.F. Zhao, J.X. Wang, Cloning and expression analysis of an O-methyltransferase (OMT) gene from Chinese shrimp, Fenneropenaeus chinensis, Fish Shellfish Immunol. 21 (2006) 284-292.

[29] S.M. Burtenshaw, P.P. Su, J.R. Zhang, S.S. Tobe, L. Dayton, W.G. Bendena, A putative farnesoic acid O-methyltransferase (FAMeT) orthologue in Drosophila melanogaster (CG10527): relationship to juvenile hormone biosynthesis? Peptides 29 (2008) 242-251.

[30] J.H.L. Hui, S.S. Tobe, S.M. Chan, Characterization of the putative farnesoic acid O methyltransferase (LvFAMeT) cDNA from white shrimp, Litopenaeus vannamei: evidencefor its role in molting, Peptides 29 (2008) 252-260.

[31] F.G. Noriega, Juvenile hormone biosynthesis in insects: what is new, what do we know, and what questions remain? Int. Schol. Res. Not. 2014 (2014) 16.

[32] E.L. Arrese, J.L. Soulages, Insect fat body: energy, metabolism, and regulation, Annu Rev. Entomol. 55 (2010) 207-225.

[33] A. Svatos, B. Kalinova, W. Boland, Stereochemistry of lepidopteran sex pheromone biosynthesis: a comparison of fatty acid-CoA $\Delta 11-(Z)$-desaturases in Bombyx mori and Manduca sexta female moths, Insect Biochem. Mol. Biol. 29 (1999) 225-232.

[34] X.R. Zhou, I. Horne, K. Damcevski, V. Haritos, A. Green, S. Singh, Isolation and functional characterization of two independently-evolved fatty acid $\Delta 12$-desaturase genes from insects, Insect Mol. Biol. 17 (2008) 667-676.

[35] H.L. Wang, M.A. Liénard, C.H. Zhao, C.Z. Wang, L.C. Christer, Neofunctionalization in an ancestral insect desaturase lineage led to rare $\Delta^{6}$ pheromone signals in the Chinese tussah silkworm, Insect Biochem. Mol. Biol. 40 (2010) 742-751.

[36] R.W. Howard, G.J. Blomquist, Ecological, behavioral, and biochemical aspects of insect hydrocarbons, Annu. Rev. Entomol. 50 (2005) 371-393.

[37] Y. Qiu, C. Tittiger, C. Wicker-Thomas, G. Le Goff, S. Young, E. Wajnberg, T. Fricaux, N Taquet, G.J. Blomquist, R. Feyereisen, An insect-specific P450 oxidative decarbonylase for cuticular hydrocarbon biosynthesis, Proc. Natl. Acad. Sci. U. S. A. 109 (2012) 14858-14863. 